\title{
Catastrophic Failure of Conservatively Treated Odontoid Fracture in the Elderly
}

\author{
James S. Harrop, MD; John Ratliff, MD²; Sonia Teufack, MD'; Jeffery Rihn, \\ $\mathrm{MD}^{3}$; Todd Albert, $\mathrm{MD}^{3}$; Alexander Vaccaro, $\mathrm{MD}, \mathrm{PhD}^{3}$ \\ ${ }^{1}$ Neurosurgery Department, Thomas Jefferson University Hospitals, Philadelphia, PA \\ ${ }^{2}$ Neurosurgery Department, Stanford University, Palo Alto, CA \\ ${ }^{3}$ Orthopedic Surgery Department, Rothman Institute, Philadelphia, PA
}

\section{ABSTRACT}

Background: Odontoid fractures are the most common type of axis injury. Elderly patients can develop odontoid fractures after minor trauma with hyperextension injuries. The optimal treatment of type II fractures is controversial.

Methods: A case of a catastrophic failure of conservative treatment for a type II odontoid fracture in an elderly patient is presented. The patient presented six years after initial diagnosis and treatment of the fracture in a collar, with an acute SCI due to progressive instability and stenosis.

Results: Cervical spine imaging revealed a posterior displaced type II odontoid fracture with sclerotic margins, severe stenosis at the level of $\mathrm{C} 2-3$ with cord compression and intrinsic cord signal abnormality.

Conclusion: Type II odontoid fractures have a high rate of non-union with non-surgical treatment and can result in cervical instability and spinal cord injury. Treatment options in the increasing elderly population with cervical spine trauma should include close observation in rigid immobilization as well as potential surgical fixation.

\section{INTRODUCTION}

Odontoid fractures are the most common type of axis injury and account for 7 to $14 \%$ of cervical spine fractures. ${ }^{7}$ They occur through the tip of the dens (type I), the base of the dens (type II), or through the body of C2 (type III). Geriatric patients can develop odontoid fractures after minor trauma with hyperextension injuries. The treatment of type II odontoid fractures remains controversial; they have been successfully managed by external immobilization and internal fixation. However, these treatments are less successful in the elderly. ${ }^{10}$ Serial observation and surgical treatment may be an option for these fractures.

\section{CASE REPORT}

An 80-year-old female presented to the emergency department (ED) after falling approximately two feet from a sitting position and sustaining a hyper-extension injury of the neck. Upon striking her head she reported loss of sensation and motor function of her upper and lower limbs and was brought in by emergency medical service. Her physical examination in the ED was significant for motor weakness in her upper extremities (2-3/5 proximally, 0-1/5 distally) and lower extremities (4-5/5); tone was increased in all extremities. Sensation was decreased in the C5 to C7 distributions bilaterally to light touch and pin prick sensation. Reflexes were increased in her lower extremities.

Plain radiographs and CT scan of the cervical spine demonstrated a posterior displaced type II odontoid fracture with sclerotic fracture margins. MRI study of the cervical spine demonstrated severe stenosis at the C2-3 level with cord compression and intrinsic cord signal abnormality on T2-weighted images. (Figure 1).

Upon further questioning, the patient and her family reported a remote history of a motor vehicle accident approximately twenty years earlier. In addition, approximately 6 years earlier, she was evaluated in the ED for progressively worsening axial neck pain. At that time she was diagnosed with a posterior displaced type II odontoid fracture on CT and MRI studies (Figure 2) and placed in a Philadelphia collar. She reported complete relief of her neck symptoms; therefore, she did not return for further follow-up evaluations or imaging and discontinued the use of a collar.
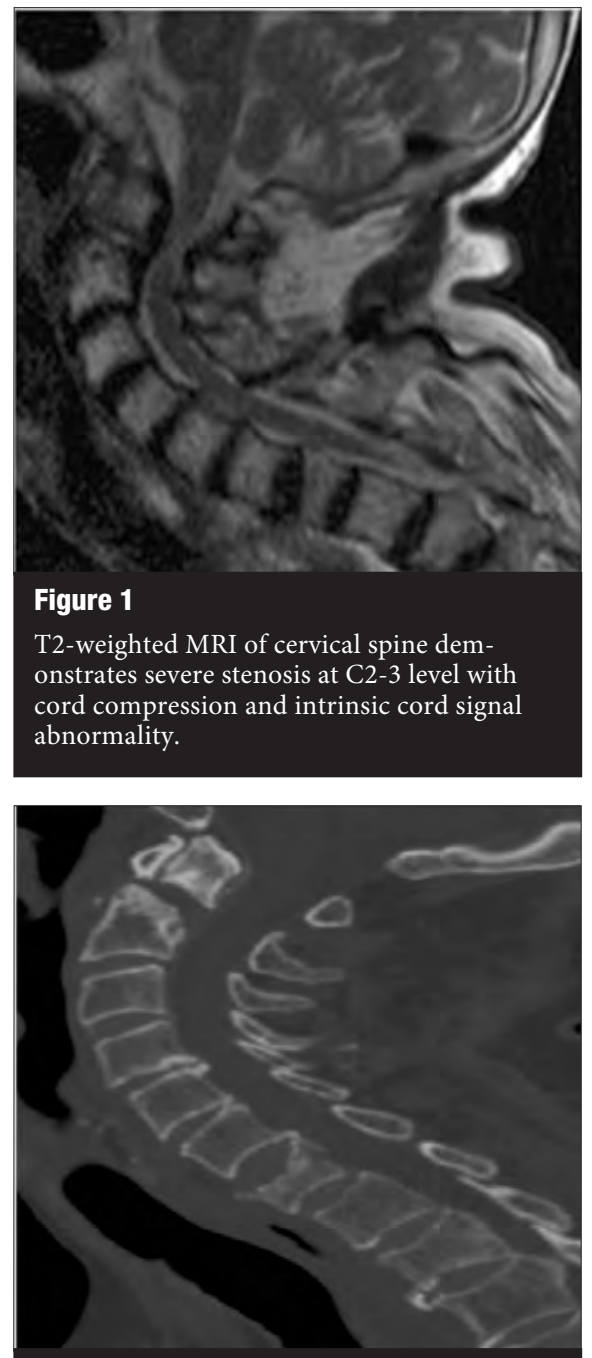

Figure 2

MRI study from 6 years previous to current presentation shows posterior displaced type II odontoid fracture.

\section{DISCUSSION}

The choice of treatment for a patient with an odontoid fracture is dependent upon the patient's symptoms, medical co-morbidities and risk of pseudoarthrosis. If a solid union of the fracture is not achieved, there is potential for the development of spinal instability and 
subsequent spinal cord injury due to encroachment of the fractured odontoid peg or a hypertrophic callus on the spinal cord. The ability to obtain bony union is dependent on patient factors as well as degree of stability provided by rigid fixation or immobilization. However, these interventions have potential morbidities. The optimal treatment must be weighted against the ability to obtain a fusion with non-rigid immobilization.

Unfortunately, the natural history and definitive treatment strategy of odontoid fractures is not clear in the literature. A recent Cochrane review in February 2008 on surgical versus conservative management of odontoid fractures failed to reveal any randomized control trials or high quality literature. ${ }^{10}$

The anatomic classification of odontoid fractures as outlined by Anderson and D'Alonzo categories these fractures as: Type I, II and III. ${ }^{1}$ This widely accepted classification system categorizes fractures based on anatomic fracture location. It has been widely utilized and has been shown to correlate with fracture healing success following various treatment modalities. For example, a type III odontoid fractures, occurring through the vertebral body and extending into the superior articular surface of the facets has a very high rate of healing with external immobilization. ${ }^{7}$ This is believed to be a result of the large amount of cancellous bone through which the fracture courses, providing a well-vascularized blood supply to this large surface area of injury.

This is to be differentiated from type II odontoid fractures, which occur at the base of the odontoid process. These fractures are often displaced due to the influence of the accessory and transverse ligaments and an environment of compromised blood flow which that adversely affects fracture hevaling. Healing is further compromised in that a small degree of displacement results in further loss of critical fracture surface area contact. Green et al reported the importance of osseous contact noting a $86 \%$ non-union rate with greater than six millimeters of fracture displacement compared to $18 \%$ with less than $6 \mathrm{~mm}$ displacement. ${ }^{5}$ Arthrodesis rate is further compromised by factors which limit the already poor vascularity to the region of the fracture. For instance, nicotine exposure has been shown to correlate with the development of a non-union in type II fractures. ${ }^{6}$ Age is also a factor in fracture healing. ${ }^{3}$ Lennarson et al reported that in patients older than fifty years there is a 21 times greater risk for non-union. ${ }^{9}$

The patient in this case opted for temporary immobilization of her neck and was afforded symptomatic relief of her axial neck pain. Unfortunately, despite the improvement in her neck pain she did not achieve a union of the odontoid fracture and manifested cervical instability. Presumably due to this instability, she developed hypertrophic changes at the C1-C2 level, resulting in canal stenosis and cord compression. The subsequent instability and canal stenosis resulted in direct cord injury, manifested by cervical myelomalecia on MR imaging. Clinically, she developed a myelopathy as noted on her examination with spasticity, increased tone, hyper-reflexia and the presence of Babinski signs. Eventually a hyper-extension mechanism to her cervical spine resulted in a direct cord contusion and a spinal cord injury.

There has been the suggestion that in the elderly population, type II odontoid fractures do not require treatment due to the low velocity forces exerted on them. Hart et al followed five patients, mean age 81 years, with a non-healed type II odontoid fractures over a mean of 4.6 years. ${ }^{8}$ He reported that no patient developed any myelopathic symptoms. Serial radiographs in these patients showed no greater than one $\mathrm{mm}$ increase in atlantoaxial excursion. The authors also noted that no patient had less than $14 \mathrm{~mm}$ available for the spinal cord in either flexion or extension plain $\mathrm{x}$-rays at the start of clinical monitoring.

This case report suggests that the period between development of clinical signs or symptoms may be greater than the follow-up offered by previous series. In this case the patient did not become clinically symptomatic until six years after her previous evaluation. She may have developed myelopathic features at a point prior to her fall, but the exact time of symptom onset is unknown. Crockard et al reported on 16 patients that presented with clinical myelopathy due to chronic non-healed odontoid fractures; $38 \%$ (6/16) of these patients did not present until greater than 5 years after initial injury. ${ }^{2}$

\section{CONCLUSIONS}

Type II odontoid fractures have a high rate of non-union with non-operative treatment techniques. Patients may develop cervical instability and subsequent spinal cord injury due to this instability. As the general age of the population increases there is an increased incidence of geriatric spine and spinal cord injuries. ${ }^{4}$ Elderly patients are at an increased risk for non-union of odontoid fractures. Operative treatment of type II odontoid fractures may prevent subsequent neurologic injuries.

This case illustrates that non-operative treatment may not be a benign solution; the natural history of this disorder has yet to be defined. Close observation with rigid immobilization and surgical treatment options should be considered as potential therapies in treatment of type II odontoid fractures.

\section{REFERENCES}

1. Anderson LD, D'Alonzo RT: Fractures of the odontoid process of the axis. J Bone Joint Surg Am 56:1663-1674, 1974.

2. Crockard HA, Heilman AE, Stevens JM: Progressive myelopathy secondary to odontoid fractures: clinical, radiological, and surgical features. J Neurosurg 78:579-586, 1993.

3. Ekong CE, Schwartz ML, Tator CH, Rowed DW, Edmonds VE: Odontoid fracture: management with early mobilization using the halo device. Neurosurgery 9:631-637, 1981.

4. Fassett DR, Harrop JS, Maltenfort M, Jeyamohan SB, Ratliff JD, Anderson DG, Hilibrand AS, Albert TJ, Vaccaro AR, Sharan AD: Mortality rates in geriatric patients with spinal cord injuries. J Neurosurg Spine 7:277-281, 2007.

5. Greene KA, Dickman CA, Marciano FF, Drabier JB, Hadley MN, Sonntag VK: Acute axis fractures. Analysis of management and outcome in 340 consecutive cases. Spine 22:18431852, 1997.

6. Hadley MN, Browner C, Sonntag VK: Axis fractures: a comprehensive review of management and treatment in 107 cases. Neurosurgery 17:281-290, 1985.

7. Hadley MN, Dickman CA, Browner CM, Sonntag VK: Acute axis fractures: a review of 229 cases. J Neurosurg 71:642-647, 1989.

8. Hart R SA, Rapp T, Clark C: Nonoperative management of dens fracture nonunion in elderly patients without myelopathy. Spine 25:1339-1343, 2000.

9. Lennarson PJ, Mostafavi H, Traynelis VC, Walters BC: Management of type II dens fractures: a case-control study. Spine 25:1234-1237, 2000.

10. Shears E, Armitstead CP: Surgical versus conservative management for odontoid fractures. Cochrane Database Syst Rev:CD005078, 2008. 